merzung von 811 u. 812 schließt sich an 809 u. 810 im besten Zusammenhange vs. 813 an: sunt etenim (so Bentl. für etiam, was doch auch geht) raris orti natalibus ignes protinus et rapti. Und die nun folgende Erörterung der Kometen und der übrigen Meteore gibt dem Dichter Anlaß zu einer glänzenden Digression über die Bedeutung dieser prodigia und ostenta für das bürgerliche und staatliche Leben - einer Digression, die uns einen Einblick in des Dichters vornehmes, echt römisches Staatsbewußtsein gewährt.

Wie steht es aber mit seinen Versprechungen in betreff der Planeten? Hat Manilius wirklich das ödeste Material eines Firmi\$us in verlorenen Büchern dichterisch geformt? Der Zodiacus mit reichster Fülle von Einwirkung auf Sage, Dichtung, auf Werke und Tage der Menschen, ein solches Feld dichterischer Tätigkeit konnten ihm die Planeten nicht bieten. Indessen - Vermutungen hierüber anzustellen, ist unnütz. Ich bemerke nur, daß selbst für ein sechstes Buch, welches die Untergänge der signa $\mathrm{zu}$ geben hätte, kein Platz zu sein scheint. Denn die Digression von vs. 711 bis zum Schlusse des V. Buches über die verschiedenen Lichtstärken und die große Zahl der signa konnte erst auf den Abschluß des Themas über ortus und obitus der signa folgen, und ich glaube, daß die nach vs. 710 vorhandene Lücke zu diesem Abschlusse groß genug war.

Hannover.

Th. Breiter.

\title{
6. Beiträge zur Erklärung und Uebersetzung der römischen Komiker.
}

Die nachfolgenden Bemerkungen zum Trinummus und den Menaechmi des Plautus, der Andria und der Adelphoe des Terentius verdanken ihren Ursprung der eingehenden Beschäftigung mit der unlängst erschienenen Uebersetzung dieser Stücke von C. Bardt (Berlin, Weidmann 1903). Ich habe die Vorzüge dieses Buches in der Monatsschrift für höhere Schulen kurz dargelegt, gelange aber doch an nicht wenigen Stellen zu einer etwas anderen Auffassung als Bardt. Daß auch diese sich in der von Bardt gewählten Form der Sprache und der Verse zum Ausdruck bringen läßt, versuche ich durch die Probe zu zeigen. Man wird leicht erkennen, daß im wesentlichen das leitende Prinzip ein engerer Anschluß an das Original war.

Trin. 510 (II, 3). Da Lesbonicus selber seiner Torheit die 
Schuld an seiner jetzigen Armut beimißt, so stimmt es nicht recht, wenn die Worte is de diuitiis meis solus superfit praeter uitam relicuos übersetzt werden mit „das einz'ge, was vom Vatergut, Mein hartes Los mir zu lassen geruht". Man könnte sagen: „Doch was von allem Reichtum allein Ich außer dem Leben noch nenne mein".

Trin. 599 (II 4). Es ist vorher die Rede davon gewesen, daß Lesbonicus mit clupers galea sarcina „Helm und Schild und Tornister " wird in die Ferne ziehen müssen; diese Gegenstände wird er nun kaum gebrauchen, wenn man ihn ,als Räuber ins Gebirge gehen " läßt; latrocinatum trifft man also eher durch "Als Kriegsknecht in die Weite gehn".

Trin. $723 \mathrm{ff}$. (III 2). Et capturum ibi spolia illum qui-meo ero aduorsus uenerit. Egomet quam extemplo arcum et pharetram mi et sagittas sumpsero, Cassidem in caput, - dormibo placidule Bardt: „Denn leider kenn' ich meine Leute Und weiß, seinem Gegner gehört die Beute. Ich nehme derweil den Helm vom Kopfe, Und forsche dafür nach dem Suppentopfe, Lasse Bogen und Köcher ruhn, Im Zelt' eirien tüchtigen Schlaf zu tun". Ungern verzichtet man auf die hübschen Pointen der witzigen Rede des Stasimus. Ich habe folgendes versucht: „Und sicher nimmt er die Beute mit, - Wer meinem Herrn entgegentritt. Ich hole mir Bogen, Köcher und Pfeile, Setz auf das Haupt mir den Helm dann in Eile, Um also gewappnet - zu friedlichem Ruhn Im Zelt ein behagliches Schläfchen zu tun".

Trin. 820 (IV 1). Den tönenden Worten des Charmides: Salsipotenti et multipotenti Jouis fratri wird die Uebersetzung: „Bruder des höchsten Jupiter, Ueber Salzges und Süßes gebietender Herr" nicht ganz gerecht. Zu dem Ethos paßt im zweiten Verse besser: "Der Salzflut weithin gebietender Herr."

Trin. 1146 (V 2). Damit Callides seine Intrigue rechtfertigt, ist es wichtig, den rechtlichen Anspruch, den Lesbonicus auf den Schatz gehabt hätte $-a$ me lege populi patrium posceret - in der Uebersetzung nicht wegzulassen; wir sagen also statt des von Bardt eingesetzten: „Hätt' er selbst das Fäßchen angestochen Und ausgeleert in sieben Wochen", vielmehr mit Plautus: „Hätt' als sein Recht er von mir verlangt Des Vaters Erbe, um das wir gebangt."

Men. $120 \mathrm{f}$. (I 2). Quando ego tibi ancillas penum, Lanam linum, aurum purpuram Bene praebeo nec quicquam eges. Bardt giebt etwas unbestimmt und gedehnt: "Ich gebe dir Zofen, täglich Brot, Kleid, Gold und Wolle weiß und rot Nebst Purpur von den schönsten Farben, Und reichlich, laß gewiß dich nicht darben"; genauer etwa so: "Ich spende dir Zofen und Essen ins Haus, Gold, Wolle und Kleider Jahr ein 
Jahr aus, Auch Purpur in den strahlendsten Farben, Und reichlich, laß gewiß dich nicht darben.

Men. 136 (I 2). Das hübsche Wortspiel zwischen Menächmus: Perii, in insidias deueni und Peniculus: Immo in praesidium: ne time kommt nicht knapp und klar genug heraus, wenn Bardt sagt: M. "Weh mir, welch Hinterhalt ist das?" T. „Zum Schutz vorhalten möcht' ich dir was." Wir ersetzen nach Bardts oft geübtem Vorgang das Wortspiel durch den Reim: M. „O weh, da lag mir der Feind auf der Lauer!" T. "Nein, nein, es schirmt dich der Freund auf der Mauer."

Men. 156 (I 2). Die echt Plautinische Derbheit des Peniculus: Oculum ecfodito per solum Mihi, Menaechme, si ullum uerbum faxo, nisi quod iusseris wird zu zahm in der Wiedergabe: „Verzeih, wenn ich's nicht zu Dank dir mache, Das Aug' im Kopf' ist so wert mir mit nichten, Als nach deinem Wunsch mich in allem zu richten." Aendert man die vorhergehenden Worte des Menächmus ein wenig: "Redst du mir darein, ist's dein eigener Schade", so schließt sich daran gut die Antwort des Schmarotzers; „Bohr mir das Auge heraus bis zur Wade, Wenn ich fürder noch jemals ohn dein Geheiß, Ein einziges Wörtlein zu sagen weiß."

Men. 252 (II 2). Es war nicht nötig, auf die kunstvolle Allitteration: Non potuit paucis plura plane proloquei ganz zu verzichten; auf 251 „Mit andern Worten: ich bin dein Knecht“; folgt passend: „Kurz, klipp und klar: du hast ganz recht."

Sondershausen. (F. f.) A. Funck.

\section{Nachtrag zu S. 80 .}

Ein neues Indicium für die Bauzeit der Pnyx, das sich mir nachträglich aufdrängt, gibt die unzweifelhafte Verwandtschaft der Pnyxanlage mit dem "Theater" des mykenischen Palastes in Phaistos, wo auch im Westhofe ein Altar- (oder Tempel-)Bau vor einer niedrigen Estrade sich erhebt. Hinter dieser führt östlich die breite Freitreppe zum Vorplatze des Megarons hinauf, während nördlich im rechten Winkel an das Heiligtum anstossend eine offenbar als Zuschauerraum gedachte Treppenanlage emporsteigt (vgl. die Abbildungen in meinem 'Homer' S. 112 und 117). So ist auch hier die Trennung des Königs und seines Gefolges auf der Estrade und der Megarontreppe, und des Volkes auf der Zuschauertreppe und im Hofe ebenso streng durchgeführt, wie in athenischen Pnyx.

E. D. 